\title{
ВЗАИМОДЕЙСТВИЕ ГРАЖДАНСКОГО ОБЩЕСТВА И ОРГАНОВ ВЛАСТИ В ЧЕЧЕНСКОЙ РЕСПУБЛИКЕ
}

\begin{abstract}
Аннотация. История России имеет разнообразный опыт общественных отношений, которые в некоторые периоды приобретали черты институтов гражданского общества. Сегодня формирование гражданского общества является актуальным вопросом, так как все, что образует государство в 21 веке, склоняется к демократическим принципам решения любых споров и проблем. Для того, чтобы осветить взаимодействие гражданского общества и органов власти, необходимо определить его природу, понять, при каких условиях гражданское общество возможно в Российской Федерации и, конкретно, в Чеченской республике. Систематизировав и обобщив возможные определения гражданского общества, можно охарактеризовать его следующим образом: это общество, в котором развиты культурные, правовые, политические и экономические отношения; акторы и институты гражданского общества взаимодействуют с государством, но не зависят от него. Гражданское общество формируют развитые правовые отношения, опирающиеся на власть. Этот процесс не имеет конечной точки завершения, он постоянно совершенствуется, достигая новых результатов и высот в построении гражданского общества. Гражданское общество может существовать только в правовом государстве. Здесь Россия сталкивается с определенными трудностями, поскольку правовое государство трудно реализовать в условиях безработицы, коррупции, поляризации общества, эгоизма в различных сферах и недостаточно развитой политической культуры.

Ключевые слова: политика, гражданское общество, Россия, Чеченская республика, политическая стабильность, политический режим, государство, интересы, ченности, безопасность.
\end{abstract}

0 снову формирования гражданского общества в Чеченской республике составляет единая позиция религиозных, национальных, общественных и правозащитных движений относительно необходимости противостояния терроризму, ксенофобии и разжиганию межнациональной розни.

В настоящее время структурами гражданского общества в Чечне являются: религиозные организации, СМИ, оппозиция, НПО, НКО и политические партии.

Взаимодействие гражданского общества и органов власти можно рассматривать на различных уровнях:

- Коммуникативный

- Информационный

- Религиозный

- Экономический

- Политический

- Правовой

Развитие гражданского общества на коммуникативном уровне важно для поддержания позитивного настроения в социальной среде, которое формируется за счет проявления индивидуальности каждого члена общества, возможности высказаться и принять участие в различных общественных мероприятиях и событиях политической жизни. На практике это проявляется в деятельности фонда «Мир Кавказу».

Цель деятельности институтов и структур гражданского общества на Северном Кавказе - содействие развитию общественных отношений, используя возможности и инструменты массовых коммуникаций. С их помощью такие структуры гражданского общества как фонд «Мир Кавказу» восстанавливают культурные связи России и Кавказа, возобновляют интерес к культурно-историческим ценностям, направляют активность политических акторов и граждан на достижение межнационального согласия, воспитывают молодежь на основных постулатах интернационализма.

На информационном уровне формируется такая важная среда как медиа-пространство. В Чеченской республике отсутствует единство такого пространства, это прослеживается в огромном количестве противоречивых материалов в СМИ и вбросах тенденциозной информации. В Северо-Кавказском медиапространстве сохраняется превосходство у ресурсов, разжигающих межнациональную рознь, что противоречит основным идеям гражданского общества.

СМИ призвано обеспечивать информацией граждан о событиях в обществе, эти события влияют 


\section{Международные отношения International Relations}

на активность граждан и, как следствие, на общественное мнение.

Средства массовой информации являются акторамисовременного политического процесса. Процесс выработки политических решений происходит во многом именно в медиа-пространстве. Это пространство - часть подсистемы гражданского общества, и играет в его формировании огромную роль, так как в гражданском обществе медиасреда обеспечивает контакт власти и социума, формируя их отношения. Медиа-пространство в гражданском обществе должно быть автономно, независимо от цензуры и власти, должно быть объективно и многогранно.

В первую очередь, гражданское общество формируют региональные СМИ. При этом важным источником информации является интернет. Институты гражданского общества в СКФО получают информационную поддержку из следующих интернет ресурсов:

- Общекавказская проблематика (пример - http:// www.kavkaz-uzel.ru);

- Официальные интернет-страницы, с проправительственной информацией;

- Интернет-ресурсы с правозащитной информацией;

- Новости и культура.

Однако в «мировой паутине» присутствуют радикальные, исламские, антигражданские сайты, деятельность которых направлена на раскол гражданского общества в России.

Многие интернет-ресурсы дают возможность гражданам с активной жизненной позицией выражать свое мнение по поводу различных социальных явлений. Органы власти не против такого положения дел, но на практике не всегда поддерживают такую форму политической активности граждан. Многие ресурсы, где происходит обсуждение политических и социальных проблем, предназначены исключительно для исполнения антистрессовой функции. Органы власти редко реагируют на мнение отдельных личностей, в основном не участвуют в публичном обсуждении и не поддерживают обсуждение тем, инициированных формирующимся в России гражданским обществом. Решение этой проблемы - в создании эффективного диалога между двумя сторонами: государством и гражданским обществом.

В Чеченской республике наблюдаются определенные позитивные тенденции в работе СМИ, так как в медиа-пространстве присутствует широкое многообразие конкурирующих информационных предприятий, которые представляют интересы различных социальных групп. Они подают материал так, как они его видят, и общество на этот материал реагирует. В чеченском медиа-пространстве ясно обозначены проблемы, но это не создает негативный имидж органам власти, а, наоборот, способствует социализации и повышению гражданского сознания.

Влияние информационных потоков на гражданское сознание и его формирование для каждого региона индивидуально, ведь сознание развивается на основе ментальности, которую определяют много факторов, в том числе- культура и религия. Именно исходя из этого, одним из уровней интеграции гражданского общества являетсядуховно-нравственный, религиозный уровень. Его можно проследить в диалоге любых общественных организаций с религиозными. Этот уровень очень противоречивый и проблемный. В Чеченской Республике существуют религиозные расхождения между различными течениями и группами, попытки разрешения которых силовым путем ведут к проявлениям религиозного экстремизма и вспышкам насилия.

В отличие от гражданского общества, антигражданское общество образуют салафистские структуры. Их основные идеи - в противостоянии суфистским принципам в общественной жизни и правлении. Они позиционируют себя как политический «Кавказский Эмират», состоящий из множества региональных группировок. Их влияние на общество сегодня осуществляется преимущественно через интернет-ресурсы. Главное оружие салафитов-исламистская идеология, которую они несут. Характерные черты подобных организаций - фанатизм, неуважение личности, отрицание любых форм диалога со светскими режимами или другими религиозными течениями. Все это мешает полноценному развитию гражданского общества в Чеченской республике.

Практика противостояния антигражданским структурам показала, что бороться с радикальным исламом можно только мирным путем. В этой связи интересно высказывание Д. Пайпса: «Исламисты сильнее там, где правящие круги наиболее непримиримы по отношению к ним, и слабее там, где правители симпатизируют исламизму». В Чеченской республике распространено учение Куна Хаджи. Это учение весьма способствует развитию гражданского общества, так как в его основных идеях - взаимопомощь и общественные работы (белхи), единство, милосердие и уступчивость.

Широкая тема для дискуссий - совместимость ислама и гражданского общества, и единого мнения по этому поводу нет. Существует два основных мнения на этот счет. Первое мнение состоит в том, что мусульманская религия и формирование гражданско- 
го общества в симбиозе может привести к серьезным конфликтам. Сторонники второго мнения убеждуны в возможности мирногососуществования ислама и гражданского общества.

Очень важный аспект взаимодействия - финансирование общественных организаций, которые представляют гражданское общество. Все процессы, связанные с этим, протекают на экономическом уровне. Финансирование проходит как помощь фондам и институтам, как государственные гранты, дотации и субсидии. Сейчас в Чеченской республике государственные дотации составляют 1 миллиард рублей, и глава Российской Федерации обещает их увеличить в 3 раза. Это связано с разными причинами, одна из которых относится ко всем другим видам финансирования интеграции гражданского общества -необходимости ограничения влияния зарубежных спонсоров, которые занимаются развитием этого института в России в своих интересах.

Сегодня, благодаря укреплению позиций России в экономике, политике и на международной арене, в России зарождается новое видение роли и места гражданского общества в стране. В этих условиях общественным организациям гораздо полезнее пользоваться внутренними ресурсами, так как неправительственные организации являются частью развивающегося гражданского общества. Они влияют и на общественно-политическую жизнь Чеченской республики. Делятся НПО на два типа - организации, которые поддерживается местными органами власти, и организации, которые поддерживаются западными структурами. Обратим внимание на второе - такие НПО независимы в выражении своего мнения и позиций, но государство им не доверяет, ввиду того, что, созданное в будущем гражданское общество будет подвержено влиянию того, кто его продвигал и спонсировал - это инструмент внешнего управления.

Чеченские НПО поддерживаются как российскими (например, «Мемориал») и зарубежными («Humanrightswatch») организациями. Интерес международных организаций к Чечне родился из-за действительно серьезных и значительных проблем, с которыми сталкивалась и сталкивается эта республика.

Экономический уровень тесно переплетается с политическим. Этот уровень формируется на базе разрешения и урегулированияпроблем и конфликтов. Проблема Чеченской республики в том, что чаще всего органы власти работают уже над последствиями проблемы или кризиса. Очень важно принять установку на опережение проблемы-уметь выявлять опасные тенденции, противоречия, и своевременно их разрешать. Здесь соединяются отношения внутри гражданского общества, традиции и идеологические принципы, которые диктуют органы власти.

Все вышеперечисленные уровни объединяются в систему, на верхнем ярусе которой расположен правовой уровень. Правовое начало приоритетно для конструирования гражданского общества. Конституционный порядок в Чечне чаще всего наводят не мирным путем. Правосудие часто не контролируется гражданским обществом, а НКО не могут его полноценно обеспечивать. Здесь проявляется вся слабость существующих связей гражданского общества и власти, что провоцирует различные противоречия.

В Чеченской республике можно столкнутся со следующими проблемами правового характера:

- Слабый уровень образования в сфере защиты прав, что ведет к неграмотности правозащитников;

- Органы власти мало занимаются организацией мероприятий, которые поддерживают целостность правовой культуры;

- Неумение защищать свои права и свободы самими гражданами.

Многогранность взаимодействия гражданского общества и органов власти определяет всю сложность организации контроля над деятельностью государства. Это способствует созданию новых гражданских институтов, которые занимаются регулированием этих вопросов. В Чечне институты гражданского общества пока еще весьма слабо представлены своими региональными структурами, и чаще всего эти структуры не стоят на позициях общественного диалога. На Северном Кавказе на сегодняшний день не существует развитого гражданского общества, но у многих республик этого региона есть хороший потенциал для формирования институтов гражданского общества и развития гражданских традиций, стимулирования гражданского участия в политических процессах.

Из институтов гражданского общества в Чеченской республике активно действуют Уполномоченный по правам человека в ЧР, Общественная палата ЧР, общественные советы и некоммерческие организации.

Большой рывок в интеграции и создании гражданского общества Чеченская республика сделала, сформировав Совет по развитию гражданского общества. Это показательно для других республик и для всей РФ, так как «авторитарная» Чечня в этом плане дает прекрасный урок демократии. Этот политический институт был создан по рекомендациям Совета при Президенте РФ от 25 июля 2013 года: «Рассмотреть вопрос о создании Советов по развитию гражданского общества и правам человека в качестве консультативных органов при главах субъектов. Совет полагает, что 


\section{Международные отношения International Relations}

такие органы, организованные по аналогии с Советом при Президенте РФ по развитию гражданского общества и правам человека, могли бы существенным образом дополнить работу, проводимую в настоящее время региональными общественными палатами, уполномоченными по правам человека, уполномоченными по правам ребенка, другими правозащитными структурами. Совет выражает готовность оказать методическую и организационную поддержку в разработке нормативно-правовой базы для создания таких Советов».

Для дальнейшего развития гражданского общества необходимо актуализировать работу общественных организаций. На сегодняшний день отсутствует активная реклама любых мероприятий на эту тему. Важно придать новизну любым формам проявления взаимодействия, создавать новые структуры и обновить старые. Необходимо показать обществу всю полезность общественных организаций, а со стороны власти - оказывать им поддержку.

Главный механизм эффективного взаимодействия гражданского общества и органов власти - диалог, благодаря которому приходит понимание всех процессов, происходящих вфедеральном центре и в субъектах РФ. Диалог создает широкие возможности для развития общества граждан, и польза от такого диалога напрямую зависит от интереса всех политических акторов к реформам в обществе.

Чеченская республика и ее народ, как уже было сказано выше - демократичны, и очень важно то, что это его естественный параметр. Естественность проявляется в большом опыте религиозных коммуникаций, этнического плюрализма и взаимоуважения. Это позволяет говорить о большой вероятности создания гражданского общества в Чечне, которое будет активно и успешно взаимодействовать с органами власти.

\section{Библиография}

1. Акимушкин О.Ф. Суфийские братства: сложный узел проблем // Тримингэм Дж. С. Суфийские ордены в исламе. М., 1989.

2. Арухов 3.С. Россия и Дагестан в новом геополитическом пространстве. Махачкала, 2006.

3. Алиев А. К., Арухов 3. С., Ханбабаев К. М. Религиозно-политический экстремизм и этноконфессиональная толерантность на Северном Кавказе. М., 2007.

4. Багдасарян В.Э, С. С. Сулакшин Высшие ценности Российского государства. Серия «Политическая аксиология». Научная монография. М.: Научный эксперт, 2012.

5. Барбашин М. Ю. Этнополитические конфликты на Северном Кавказе //Независимая газета. 12.08.1999.

6. Большаков А. Г. Политический конфликт: возможности управления и исследовательские традиции. Казань, 2004.

7. Гаммер Д. М. Шамиль. М./1998.С.11

8. Гушер А.И. «Основы политики России на Северном Кавказе»/ М. 2011.

9. Дибиров А.- Н.3. Политический экстремизм и дагестанская идентичность // Актуальные проблемы противодействия национальному и политическому экстремизму: Материалы Всероссийской научнопрактической конференции. Том І.- Махачкала: «Лотос», 2008.

10. Дмитриев А. В. Конфликтология М./ 2002. С. 155.

11. Дудова С. С. Анализ природы конфликтов в Карачаево-Черкесской и Кабардино-Балкарской республиках. Мир на СК. Сим.№ 2. Национальная политика, этнополитика и этноконфликтология на СК. 2004 г..

12. Зелимханов 3. М., Ханбабаев К. М. Политизация ислама на Северном Кавказе (на примере Дагестана и Чечни). Махачкала, 2000.

13. Керимов Г.М. Возникновение суфизма и основы его учения // Государство, религия, Церковь в России и за рубежом, 2010.

14. Кириллина С.А.. Ислам в общественной жизни Египта (вторая половина XIX- начало XXв.) М..1989.

15. Кисин С., Мурадов М.. Террористы разбрелись по Кавказу // Коммерсант. 26.08.2006.

16. Леонов Н.И. Хрестоматия по конфликтологии. Москва.: Московский психолого-социальный институт, 2004.

17. Манойло А.В. Технологии несилового разрешения современных конфликтов. / А. В. Манойло; под ред. проф. А.И. Петренко.- М.: Горячая линия - Телеком, 2008.

18. Манойло А.В. Мирное разрешение конфликтов: национальные концепции, модели, технологии / А. В. Манойло // Власть.-2008.

19. Мантаев А. А. «Ваххабизм» и политическая ситуация в Дагестане.- Москва, 2002;

20. Мурклинская Г. Следствие выяснило источник финансирования ваххабитов // Известия. 26.02.1998. 


\section{Политическая стабильность}

21. Муталиев Т. Х. Тернистый путь народа // Ингушетия и ингуши / М. Д. Яндиева.- Москва: Новая Планета, 1992.- Т. II.

22. Новицкий И. Я. Управление этнополитикой Северного Кавказа/ Краснодар: «Здравствуйте», 2011.

23. Светлов В.А. Управление конфликтом. СПб./ «Росток», 2003.

24. Семенов В.А. Конфликтология: история, теория, методология. СПб., СЗАГС, 2008.

25. Тишков В.А., доклад на конференцию «Будущее российского федерализма: политический и этнический факторы»/ 25-26 марта 2000 г.

26. Токарев С.А. Религия в истории народов мира.- Москва: Республика.

27. Тримингэм Дж.С. «Суфийские ордены в исламе» С.188.

28. Харенко А.А. Горными тропами Кабардино-Балкарии: Спутник туриста.- Нальчик: Эльбрус, 1972.

29. Этингер Я. Межнациональные конфликты в СНГ и международный опыт // Свободная мысль.- 1993.№ 3.- С. 89.

30. Яхъяев М.Я. Истоки и смысл фанатизма.- Махачкала: ИПЦ ДГУ, 2005.

31. Северный Кавказ в национальной стратегии России/ Под ред. В. А. Тишкова. М.: ФГНУ «Росинформагротех». 2008.

32. Стратегия социально-экономического развития Республики Дагестан до 2025 / Материалы проекта документа-Республика Дагестан, 2011.

33. Съезд народов Дагестана.- Махачкала: Издательство «Лотос», 2011.

34. Учеб. пособие для вузов/Сост. и отв. редактор А. А. Радугин., 2-ое изд. дополн. и перераб.- М Центр, 2003.-336с

35. Бочарников И. В. О государственной идеологии России // Международные отношения.- 2013.- 1.- С. 22-27. DOI: 10.7256/2305-560X.2013.01.3.

36. И.В. Бочарников Северо-Кавказский регион: проблемы и перспективы реализации государственной политики России // Международные отношения.- 2012.- 1.- C. 36-45.

\section{References (transliterated)}

1. Akimushkin O. F. Sufiiskie bratstva: slozhnyi uzel problem // Trimingem Dzh. S. Sufiiskie ordeny v islame. M., 1989.

2. Arukhov Z.S. Rossiya i Dagestan v novom geopoliticheskom prostranstve. Makhachkala, 2006.

3. Aliev A. K., Arukhov Z.S., Khanbabaev K. M. Religiozno-politicheskii ekstremizm i etnokonfessional'naya tolerantnost» na Severnom Kavkaze. M., 2007.

4. Bagdasaryan V.E, S. S. Sulakshin Vysshie tsennosti Rossiiskogo gosudarstva. Seriya «Politicheskaya aksiologiya». Nauchnaya monografiya. M.: Nauchnyi ekspert, 2012.

5. Barbashin M. Yu. Etnopoliticheskie konflikty na Severnom Kavkaze //Nezavisimaya gazeta. 12.08.1999.

6. Bol'shakov A. G. Politicheskii konflikt: vozmozhnosti upravleniya i issledovatel'skie traditsii. Kazan», 2004.

7. Gammer D. M. Shamil». M./1998.S.11

8. Gusher A. I. «Osnovy politiki Rossii na Severnom Kavkaze»/ M. 2011.

9. Dibirov A.- N.Z. Politicheskii ekstremizm i dagestanskaya identichnost» // Aktual'nye problemy protivodeistviya natsional'nomu i politicheskomu ekstremizmu: Materialy Vserossiiskoi nauchno-prakticheskoi konferentsii. Tom I.- Makhachkala: «Lotos», 2008.

10. Dmitriev A. V. Konfliktologiya M./ 2002. S. 155.

11. Dudova S. S. Analiz prirody konfliktov v Karachaevo-Cherkesskoi i Kabardino-Balkarskoi respublikakh. Mir na SK. Sim.№ 2. Natsional'naya politika, etnopolitika i etnokonfliktologiya na SK. 2004 g..

12. Zelimkhanov Z. M., Khanbabaev K. M. Politizatsiya islama na Severnom Kavkaze (na primere Dagestana i Chechni). Makhachkala, 2000.

13. Kerimov G. M. Vozniknovenie sufizma i osnovy ego ucheniya // Gosudarstvo, religiya, Tserkov» v Rossii i za rubezhom, 2010.

14. Kirillina S. A.. Islam v obshchestvennoi zhizni Egipta (vtoraya polovina XIX- nachalo XXv.) M..1989.

15. Kisin S., Muradov M.. Terroristy razbrelis' po Kavkazu // Kommersant. 26.08.2006.

16. Leonov N. I. Khrestomatiya po konfliktologii. Moskva.: Moskovskii psikhologo-sotsial'nyi institut, 2004.

17. Manoilo A. V. Tekhnologii nesilovogo razresheniya sovremennykh konfliktov. / A. V. Manoilo; pod red. prof. A. I. Petrenko.- M.: Goryachaya liniya - Telekom, 2008. 


\section{Международные отношения International Relations}

18. Manoilo A. V. Mirnoe razreshenie konfliktov: natsional'nye kontseptsii, modeli, tekhnologii / A. V. Manoilo // Vlast».-2008.

19. Mantaev A. A. «Vakhkhabizm» i politicheskaya situatsiya v Dagestane.- Moskva, 2002;

20. Murklinskaya G. Sledstvie vyyasnilo istochnik finansirovaniya vakhkhabitov // Izvestiya. 26.02.1998.

21. Mutaliev T. Kh. Ternistyi put» naroda // Ingushetiya i ingushi / M. D. Yandieva.- Moskva: Novaya Planeta, 1992.- T. II.

22. Novitskii I. Ya. Upravlenie etnopolitikoi Severnogo Kavkaza/ Krasnodar: «Zdravstvuite», 2011.

23. Svetlov V. A. Upravlenie konfliktom. SPb./ «Rostok», 2003.

24. Semenov V. A. Konfliktologiya: istoriya, teoriya, metodologiya. SPb., SZAGS, 2008.

25. Tishkov V. A., doklad na konferentsiyu «Budushchee rossiiskogo federalizma: politicheskii i etnicheskii faktory»/ 25-26 marta $2000 \mathrm{~g}$.

26. Tokarev S. A. Religiya v istorii narodov mira.- Moskva: Respublika.

27. Trimingem Dzh.S. «Sufiiskie ordeny v islame» S.188.

28. Kharenko A. A. Gornymi tropami Kabardino-Balkarii: Sputnik turista.- Nal'chik: El'brus, 1972.

29. Etinger Ya. Mezhnatsional'nye konflikty v SNG i mezhdunarodnyi opyt // Svobodnaya mysl»._ 1993._ № 3._- S. 89.

30. Yakh"yaev M. Ya. Istoki i smysl fanatizma. - Makhachkala: IPTs DGU, 2005.

31. Severnyi Kavkaz v natsional'noi strategii Rossii/ Pod red. V. A. Tishkova. M.: FGNU «Rosinformagrotekh». 2008.

32. Strategiya sotsial'no-ekonomicheskogo razvitiya Respubliki Dagestan do 2025 / Materialy proekta dokumentaRespublika Dagestan, 2011.

33. S"ezd narodov Dagestana.- Makhachkala: Izdatel'stvo "Lotos», 2011.

34. Ucheb. posobie dlya vuzov/Sost. i otv. redaktor A. A. Radugin., 2-oe izd. dopoln. i pererab.- M Tsentr, 2003.-336s.

35. Bocharnikov I. V. O gosudarstvennoi ideologii Rossii // Mezhdunarodnye otnosheniya.- 2013.- 1.- C. $22-27$. DOI: 10.7256/2305-560Kh.2013.01.3.

36. I. V. Bocharnikov Severo-Kavkazskii region: problemy i perspektivy realizatsii gosudarstvennoi politiki Rossii // Mezhdunarodnye otnosheniya.- 2012.-1.- C. 36-45. 